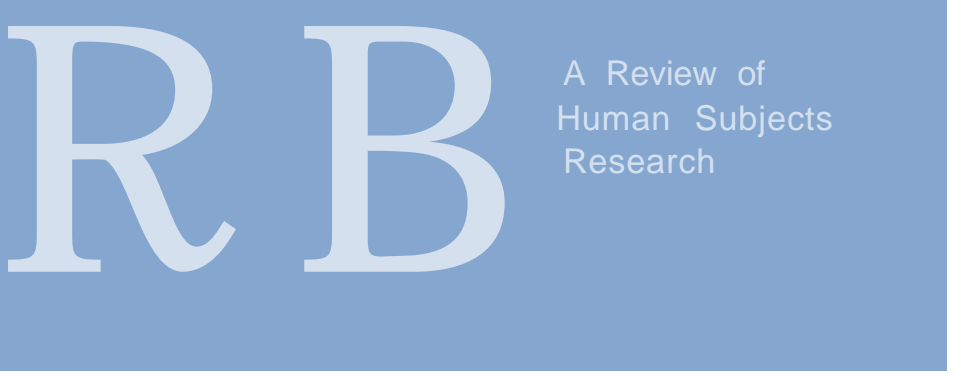

Volume 19, Numbers 3, 4

May-August 1997

Structuring the Review of Human Genetics

Protocols Part II: Diagnostic and Screening

Studies by Kathleen Cranley Glass, Charles Weijer,

Trudo Lemmens, Roberta M. Palmour, and Stanley H. Shapiro

"There is no substantive due process right to conduct human-subject research": The Saga of the Minnesota Gamma Hydroxybutyrate Study

by Dale E. Hammerschmidt

OBITUARY

CALENDAR

\title{
Structuring the Review of Human Genetics Protocols Part II: Diagnostic and Screening
}

Studies by Kathleen Cranley Glass, Charles Weijer,

Trudo Lemmens, Roberta M. Palmour, and Stanley H. Shapiro

nstitutional review boards (IRBs) are increasingly confronted with rapidly developing genetic technologies. As a consequence, genetics protocols often contain material unfamiliar to many IRB members. As with other protocols, the IRB must evaluate the validity and value of the research, subject eligibility criteria and recruitment strategies, quantification or prediction of risks and benefits, disclosure of information to prospective subjects, privacy and confidentiality, and protocol monitoring. In reviewing genetics research, the challenge for IRBs is to recognize when new issues are presented, and to determine whether they are addressed appro- priately by the investigators before recommending approval, amendment, or disapproval of protocols.

In previous work, we addressed the review of gene localization and identification protocols. ${ }^{1}$ We have designed the present article to assist investigators and IRB members in their review of genetic diagnostic and screening protocols. We provide a general description of diagnostic and screening studies, set out a checklist/ critical path identifying issues for IRB review (table 1), and discuss in greater detail several points of controversy raised by this kind of research. A glossary is provided for terms that are not defined in the body of the text (table 2). Because gene localiza-

tion and identification protocols and genetic diagnostic and screening studies frequently contain overlapping issues, we recommend that the two articles be read together.

\section{Genetic Diagnostic and Screening Protocols}

Distinguishing Diagnostic and Screening Tests. Genetic tests are used in two distinct sets of circumstances: diagnosis and screening. Clinicians use diagnostic tests either to confirm or to exclude certain diagnoses in their patients. A genetic diagnostic test is a specific method used to identify the genetic status of an individual suspected of being at high risk for a particular inherited condition based on evidence such as family history or clinical profile. ${ }^{2}$ Screening has been defined as the identification, among apparently healthy individuals, of those who are sufficiently at risk of a specific disorder to justify a subsequent diagnostic test or procedure. ${ }^{3}$ In this sense, screening involves testing populations rather than individuals. $\mathrm{Ge}$ netic screening differs from a diagnostic test in that a screening test may be insufficiently sensitive (as we discuss below) to allow definitive diagnosis, and therefore calls for further testing, rather than immediate therapeutic intervention. ${ }^{4}$ The National A cademy of Sciences has defined genetic screening as a search in a population for persons possessing genotypes that are already associated with disease or predispose to it, may lead to disease in their descendants, or may be the cause of other variations not known to be associated with disease. ${ }^{5}$ Screening programs are frequently aimed at asymptomatic individuals or groups with the goal of early detection to prevent or ameliorate a disease. The populations or groups evaluated are most frequently apparently healthy individuals, independent of any family history of a disease.

Diagnostic tests and screening tests are not always easily distinguished. Prom a technical standpoint, the tests used for diagnosing individuals or screening groups may be identical. However, while 


\section{Table 1. Schema for IRB Review of Genetic Diagnostic/Screening Protocols.}

Questions marked with an asterisk refer to issues of particular relevance in genetics protocols.

\section{Background and justification}

What questions does the research address? Has the investigator demonstrated that the research has scientific or medical value?

How does the proposed study relate to previous work? Have any innovative aspects been adequately justified?

* If the study concerns a diagnostic test, in what (clinical or other) situations will this test be helpful?

\section{Research design}

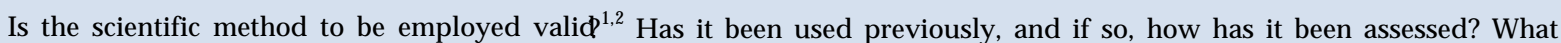
quality controls are built into the method? ? $^{3,4}$

Is the planned statistical analysis appropriate: i.e., is it likely to provide valid answers to the study questions?

* For diagnostic studies, how is the condition (or risk thereof) currently diagnosed? Will the new diagnostic strategy be compared with the best available standard test?

* What is known about the nature and frequency of genetic polymorphisms related to the study condition?

If the study is a diagnostic protocol: How does the existence of polymorphisms affect the ability to define risk thresholds (cutoffs)?

If the study is a screening protocol: How does the frequency of polymorphisms affect the feasibility of population screening?

* Is it likely that other genes are required for full trait expression? ${ }^{5}$

* If subjects will be informed of the test results, does the study design provide for an adequate assessment of the psychosocial impact of genetic testing?

\section{Procedures}

What research-specific procedures are involved in the study (e.g., physical examinations, blood tests, tissue/ tumor donation, questionnaires, interviews, etc.)? How many? How often? How much time will they take? Are they all required to answer the research question?

* If long-term follow-up is required, over what period of time will this take place?

* What are the procedures for obtaining or maintaining information in a data/ DNA bank (e.g., use of identifiers, limitation on access, need for a second consent, sharing with other investigators, duration of storage, future subject contact) $?^{6-9}$

* Are adequate procedures in place for maintaining security and confidentiality of data/ records/ database information specified clearly (e.g., encryption, use of unique identifiers, sequestering of records) ${ }^{10}$

Subject selection [for questions related to recruitment of families at risk, see our earlier paper ${ }^{6}$ ]

* How is the study population defined?

If the study is a diagnostic protocol: Does it include affected and/ or unaffected individuals, related or unrelated? Are healthy controls included?

If the study is a screening protocol: How is the population at risk defined and why was it chosen (general population? targeted population?-prenatal, newborn, young children, adolescents, adults, at-risk population)

Have the eligibility criteria been justified? Do they strike a defensible balance between scientific validity and generalizability (i.e., is the study population sufficiently, but not unduly, restricted so as to yield interpretable results)?

How are subjects to be recruited? If remuneration is provided, is the amount or nature appropriate?

* Does the protocol target members of an indigenous or other identifiable community? Have appropriate measures been included to take account of this fact (e.g., approaching community leaders, soliciting collaboration where appropriate)?

* Does the protocol include or target newborns or other young children? If so, is the study condition one that manifests or requires initiation of preventive measures in childhood? ${ }^{10}$ Have provisions been made for children's assent, where appropriate, and consent of the parents/ guardians? ${ }^{11,12}$

Does the protocol include or target adolescent subjects? If so, is the study condition one which has implications for health at this age? For reproductive planning? Have provisions been made for counseling, taking account of any special needs of subjects in this age group? ${ }^{10}$

Does the protocol include incompetent adults? Is there a valid alternative to their participation $?^{10}$ If not, have provisions been made for assent, where appropriate, and/ or proxy consent? ${ }^{10}$

If children or incompetent adults are included in the protocol, is there any conflict of interest between the research subjects and the parent/ guardian giving consent? If so, how will the subjects' interests be protected? 
Table 1. Schema for IRB Review of Genetic Diagnostic/Screening Protocols. (Continued)

Does the protocol involve other vulnerable populations (e.g., patients with Alzheimer disease or psychosis who have periods of fluctuating competence)? Have their special needs been taken into account? ${ }^{13}$

Risks and benefits [for questions related to nonpaternity, publication of pedigrees, and risks resulting in discrimination, see our earlier paper on gene localization and identification studies $\left.{ }^{6}\right]$

Is the importance of the research question sufficient to justify the research-specific risks? ${ }^{14,15}$ Have risks to subjects been minimized? ${ }^{16}$

* Will participation in the study result in any benefit to subjects? Will the results be informative for participants in terms of life or health choices?

* Will knowledge gained by the subjects about their current or future health or their carrier status pose additional risks to them, such as risks to insurability, ${ }^{17}$ employability, immigration, paternity suits, educational opportunities, or social stigma? Have adequate provisions been made for privacy and confidentiality of subject information?

* Could the research result in stereotyping or stigmatizing a particular community or cultural group? Have investigators taken steps to approach the group involved and solicit comments where appropriate? ${ }^{18-22}$

* Is psychological support required for those determined to be at risk? How will it be provided?

Information to subjects [for questions pertaining to the participation of families, see our earlier paper ${ }^{6}$ ]

Does the information to be provided to prospective subjects adequately inform them of: what is being studied and why; details about study procedures, known risks, discomforts, and benefits; and alternatives to participation?

* Will subjects be adequately informed if the study objective is to assess unknown risks?

* Will subjects be adequately informed of any limitations of the test/ screen results as a predictor of clinical risk?

* Will subjects be informed of any special risks associated with the study (e.g., risks to privacy, confidentiality, insurability, employability, immigration status, paternity suits, educational opportunities, or social stigma)? ? $^{17,23,24}$

* If no immediately useful or interpretable information of relevance to subjects is likely to result from the study, will this be disclosed adequately to subjects in advance of their participation?

* Will subjects be told of their right to withdraw from the research without penalty or loss of benefits? ${ }^{25}$ Will they be advised of any consequences of, or limitations on, withdrawal, including withdrawal of data or DNA samples?

Will the general study results be made available to subjects? ${ }^{24}$

* Could other clinically relevant information be uncovered during the study? Who will disclose it (investigator, genetic counselor, family physician)?

* Will genetic counselors be available to transmit relevant information to subjects?

* Will subjects be given the opportunity not to receive their test results?

* Will there be any monetary costs to the subject associated with participation (including the cost of counseling)? Will this be disclosed to subjects? ${ }^{26}$

\section{Commercial interests}

* Will subjects be informed of anyone having a commercial interest in the research (e.g., investigator, pharmaceutical or biotechnology company sponsor, university or hospital, government agency)? ?77,7

* When commercial products may eventually be developed from biological materials removed from subjects, will subjects be asked to waive any rights or control over the tissue? If they refuse, will they be allowed to participate?

Table references appear on page 13.

diagnostic tests and screening tests may be technically identical, they have different goals. Diagnostic testing of an individual at risk assists in confirming or ruling out diagnoses. For example, persons with a family history of Huntington disease may choose to be tested before exercising reproductive options, or during the early stages of pregnancy.

There are several generally accepted rationales for genetic screen- ing. The best known are early diagnosis and treatment (e.g., universal newborn PKU screening). Screening might be done on populations in the context of reproductive counseling, either preconception or antenatal (e.g., Tay-Sachs screening in the A shkenazi Jewish community or thalassaemia in communities of Mediterranean origin) or monitoring of normal pregnancies as one component of primary preventive care (ultrasound visualiza- tion for gross physical malformations, maternal serum alpha-fetoprotein quantification for spina bifida and other abnormalities, and chromosomal evaluation of pregnancy in mothers over the age of 35). Screening is also important as a research tool in a variety of situations. Research might be undertaken: to estimate the frequency and distribution of genetic variation in a community or population (e.g., pilot studies leading to the 
development of screening programs for Tay-Sachs disease carriers); to determine the frequency of particular mutations (e.g., frequency of particular cystic fibrosis mutations) or their presence in particular geographic regions or populations (e.g., BRCA 1 in Ashkenazi Jewish women); or to determine the accuracy of using nongenetic tests as risk predictors (e.g., accuracy of cholesterol values in childhood as predictors for risk of hypercholesterole mia). While not screening in the clinical sense, population geneticists screen groups to map the origins and migration of human populations and to identify genetic factors related to resistance or susceptibility to disease.

Levels of Genetic Testing. There are five operational levels of genetic testing based on different screening techniques:

Clinical phenotype: structural or functional changes associated with the genotype may be obvious or easily identifiable. For example, infants with spina bifida, achondroplasia, or cleft palate are easily identifiable at birth.

Chromosomes: the number and structure of chromosomes may be surveyed in appropriately cultured and stained cells using a light microscope. This is done with amniocytes when women of advanced maternal age are screened to detect a fetus affected by chromosomal aberrations, or in infants suspected of having Down syndrome or other chromosomal abnormalities.

M etabolite level: blood, urine, and other bodily fluids may be tested for evidence of metabolic disorder secondary to genetic disorder. Measurement of phenylalanine in neonatal blood as a screen for PKU is an example. Diagnosis of Lesch-Nyhan disease may be suspected on the basis of elevated levels of urinary uric acid.

Polypeptide or protein level: the mutant protein, that is, the gene product itself, may be identifiable. In Tay-Sachs, carriers may be identified by electrophoresis or measurement of serum hexosaminidase A activity. Enzyme assay is the most generalizable way of diagnosing Lesch-Nyhan disease.
D NA level: the DNA itself may be analyzed for genetic mutations known to occur in specific populations or families. Molecular testing is used in a variety of circumstances, including general population screening, screening groups at risk, or diagnostic tests for individuals at risk. Techniques such as polymerase chain reaction (PCR), single strand gel electrophoresis, single strand conformational polymorphism (SSCP), multiplexing, and direct sequencing of DNA are used. ${ }^{6}$

\section{Developing a G enetic Test.} There are a number of stages in developing diagnostic and screening tests. IRBs will encounter protocols in all of these stages before they are incorporated into clinical practice. Initially, an indication may emerge from a basic study that a test might reveal, in a costeffective manner, a condition that would benefit from medical attention or that might be useful to members of the general public. The test would operate at one of the levels discussed above (clinical phenotype, metabolite, polypeptide, or DNA) and could then be used to assist diagnosis. To move such a test into screening, the condition should be relatively common in the population selected for screening. Pilot projects would then be required to assess the test's performance (sensitivity and specificity, discussed below). Until this is established, test results are meaning. less to the individuals. For this reason, many of these pilot studies are done with anonymous samples. Once performance has been demonstrated, additional studies may be done to determine the cost effective ness of applying the test to larger populations. Psychosocial or other issues that may emerge from having the test available may also be studied. While numerous ethical issues remain after the test or screen has been developed and passes into clinical practice, these will be outside the IRB's purview.

\section{Schema for Review}

Table 1 contains a series of questions IRBs may want to ask when reviewing testing or screen- ing protocols. Some of the questions reflect the IRB's need for information similar to that which would arise for any protocol. Others refer specifically to issues arising in human genetics protocols. $\mathrm{N}$ ot all questions are relevant for all protocols, nor is the list of questions exhaustive. IRBs may add other questions to those we have provided. They may also refer to our previous paper for questions concerning: (1) the storage and future use of DNA; (2) recruitment of families at risk; (3) nonpaternity; (4) social discrimination; and (5) the publication of pedigrees. ${ }^{1}$

Given the novelty and technical complexity of many genetic studies, not all IRBs will have the expertise to deal with all of the questions posed. In these cases, IRBs should consult with specialists in appropriate disciplines.

\section{Discussion}

The review of genetic diagnostic and screening protocols may raise many ethical issues. In our earlier work, we identified and discussed issues relating to the evaluation of a protocol's value and validity, family participation in research, and disclosure of research results to subjects. ${ }^{1}$ The discussion below is limited to three issues that we believe are of central importance for appropriate review of these protocols: uncertainty of clinical prediction, research with communities, and confidentiality of test results.

Genetic Testing and Screening and the Uncertainty of Clinical Prediction. It is often not possible to predict risk perfectly with a genetic test. The potential clinical consequences of a test, as well as the implications of actions based on these results, make it essential that investigators appreciate the clinical complexities and also that they explicitly provide a mechanism for explaining this information to the research subjects. ${ }^{7}$

Receiving accurate information on the anticipated predictive value of a testing or screening protocol is important to an IRB for a number. of reasons. First, the accuracy of 
the results and their consequent usefulness to research subjects will be a determining factor in the investigator's and the IRB's consideration of whether individual research test results should be disclosed to subjects. ${ }^{1}$ Second, in undertaking its risk-benefit analysis, the IRB must weight the scientific, clinical, and in some cases social usefulness of the test or screen. The predictive value will likely affect all of these. ${ }^{1}$

The following are some of the factors that affect the scientific, clinical, and moral weight of information resulting from genetic diagnostic testing and screening protocols.

Quality of the technology, equipment or laboratory facilities, and personnel. How good is the technology or equipment being used for the test? How difficult are the results to interpret and how skilled are those charged with the interpretation? What quality control procedures are in place for dealing with ambiguous results? The issue of ambiguity is clear in the context of a prenatal ultrasound, for example, which requires clinical judgment to interpret. The same is true for the use of MRI to evaluate the presence and staging of tumors. Test results are therefore only as good as the equipment and personnel involved. Some results are important for making medical or life choices, or may have a considerable psychosocial impact. Subjects who receive test results must know whether those results are in any way limited or compromised.

In the United States, the Clinical Laboratories Improvement Act (CLIA) requires the accreditation of virtually all laboratories providing genetic test results. ${ }^{8}$

Sensitivity or specificity of the test. For every laboratory or diagnostic procedure there is a set of fundamental questions that should be asked about the characteristics of the test itself. First, if the disease (or genetic mutation or gene product) is present, what is the likelihood that the test result will be positive? In other words, how sensitive is the proposed test? Second, if the disease (or genetic mutation or gene product) is absent, what is the probability that the test result will be negative? That is, what is the specificity of the proposed test. ${ }^{3}$

IRB members should ask how frequently a result is expected to be falsely negative or falsely positive, and what impact this will have on the person receiving the results. For example, there should be a very low false negative rats for screening tests, such as the maternal alpha-fetoprotein exam, and a low false positive rate for the follow-up diagnostic test (chromosome analysis or ultrasound visualization of abnormalities) because of the potential for erroneously aborting an unaffected fetus.

The role of false positives and false negatives should be thoroughly explored in the context of the importance of the results and the existence of confirmatory testing. The prenatal alpha-fetoprotein test, for example, gives many false positive results, and it becomes relevant, therefore, how these results are handled. What steps will be taken with a positive test re sult? Will the test be repeated? If positive a second time, will the test be repeated again? Is there an additional diagnostic tool that can be employed (e.g., ultrasound, amniocentesis) to confirm the accuracy of the testing process?

Penetrance, age of onset, and clinical expression. Genetic information concerning many disorders remains probabilistic in nature For example, in many diseases, not all who carry a gene will go on to develop the disease (incomplete penetrance). Such is the case with BRCA 1. Nor are all noncarriers absolutely protected from disease, as with colon cancer or Alzheimer's disease. In many diseases there may be multiple genes responsible, no one of which is found in all individuals with the disorder. Without knowing more about these genes, one cannot tell anything about which are deterministic in nature, and what protective genes may balance them. Even in monogenic conditions, there may be variability in the expression of the disease. The degree of severity cannot usually be predicted by a genetic test, even a test for a particular mutation. Sickle-cell anemia is an example. Age of onset may also vary greatly, as with breast cancer and coronary heart disease in familial hypercholesterolemia. ${ }^{7}$ Both the protocol and the information provided to subjects should accurately reflect how these variables apply to the condition being tested.

Reliability of the results. When is a genetic test ready for clinical use? Should physicians be recommending genetic testing as soon as the first research results are published, or should they wait until more studies can confirm (or disprove) the initial findings? These questions take on increased importance as genetic tests become commercially available. Investigators should provide IRBs with information concerning the stage of development of the test.

A vailability of therapy or pre vention or implications for life choices. Diagnostic tests are generally used when patient clinical care or life choices can be influenced. Where safe and effective therapy or prevention strategies exist that have been accepted as standard practice, providing the information necessary for patients to make appropriate choices is clearly in their best interests. For example, clinical detection of familial adenomatous polyposis (FAP) through testing persons at risk allows for regular follow-up with colonoscopy and surgical removal of the colon where required. Where there is no therapy, and prevention strategies are unproven, as with BRCA1, the question of testing is ethically more questionable. IRBs may have to deal with the fact that certain individuals with a defined family history and known segregating mutations may demand to have a test available. Is the inability to offer treatment sufficient grounds not to develop the test?

IRBs should distinguish between diagnostic testing of individuals and screening programs aimed at groups by asking what role the test results will play in the lives of the recipients. An individual patient for whom diagnostic testing

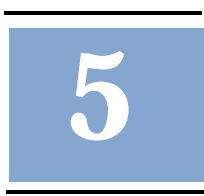




\section{Table 2. Glossary}

amniocytes - cells taken from the amniotic sac during pregnancy, in order to determine the chromosomal constitution of the genotype of the developing embryo.

chromosome - subcellular bodies composed of highly condensed, double-stranded DNA molecules, and containing a linear, end-to-end arrangement of genes.

DNA (deoxyribonucleic acid) - a double-stranded molecule (held together by weak bonds between base pairs of nucleotides) that encodes genetic information.

gene - the fundamental physical and functional unit of heredity, constituting an ordered sequence of nucleotides located in a particular position on a particular chromosome.

familial adenomatous polyposis (FAP) - a highly heritable precancerous gastrointestinal condition.

gel electrophoresis - a commonly used method for the rapid separation of a mixture of molecules (such as DNA, RNA, or proteins) according to their size and/ or electrical charge. The mixture is placed in a well at one end of a slab of porous gelatinous material such as agarose and an electrical charge applied, causing the molecules to migrate through the gel with different speeds.

genotype - the genetic constitution of an organism or group of organisms.

hexosaminidase A - an enzyme found in blood, brain, and other tissues.

hypercholesterolemia - a syndrome in which there are excessive amounts of cholesterol in the plasma. One form, familial hypercholesterolemia, is highly heritable. metabolite - a naturally occurring biochemical that is either a precursor or a product of metabolism (e.g., foodstuff, vitamin, metabolic intermediate, waste product).

mRNA (messenger RNA) - mRNA's chemical composition is similar to DNA, but with ribose sugar rather than deoxyribose sugar and a base sequence that is complementary (i.e., the mirror image) of the DNA molecule from which it was formed. mRNA is the template on which protein is synthesized, forming the crucial connecting link between the information contained in the gene and the gene product.

multiplexing - the process of simultaneously amplifying several fragments of DNA by incubating multiple sets of primers with the DNA and taq polymerase. pedigree - a diagram of the family structure that indicates the numbers and genders of family members, their relationship to the proband and to one another, and their status with respect to one or more hereditary conditions.

phenotype - the observable physical expression of a particular gene or combination of genes, or of the interaction of genotype with the environment.

phenylalanine - one of the common amino acids in proteins.

polymerase chain reaction (PCR) - a technique for amplifying a short DNA base sequence many times by providing a set of chemical markers (primers) that define the beginning and ends of the sequence to be amplified, then subjecting the mixture to repeated cycles of heating (during which new DNA is made by taq polymerase) and cooling (to return the structure to the double-stranded configuration). Under specified conditions, PCR can be used to detect the existence of a defined sequence in a DNA sample.

polypeptide or protein - a peptide formed by the union of an indefinite (usually large) number of amino acids by peptide links (-NH-CO-). The polypeptide is the secondary product of a gene.

polymorphism - the occurrence in the same population of two or more genotypes in such proportion that the rarest cannot be maintained by recurrent mutation alone. The term is used to differentiate between rare and common alleles.

proband - the affected person through whom a pedigree is discovered or explored.

RNA (ribonucleic acid) - a chemical found in the nucleus and cytoplasm of cells; a single-stranded nucleic acid similar to DNA, but with ribose sugar rather than deoxyribose sugar and uracil rather than thymine as one of its bases.

\section{single strand conformational polymorphism}

(SSCP) - a technique for the detection of a mutation that denatures DNA by heating, then quickly cooling it so that the strands no longer remain paired, and single strands with mutations will be recognizable on gel electrophoresis by migrating differently.

Taq - heat stable DNA polymerase purified from Thermophilus aq. (a single-celled organism that lives in thermal vents in the ocean floor). is recommended should be in a position to understand his or her risk status and discuss the advantages, disadvantages, and implications of a genetic test with a knowledgeable physician or genetic counselor before making a choice as to whether to undergo a genetic diagnostic test. This would include any health or life choices that might be affected by the knowledge the test would bring, as well as the psychosocial impact of receiving test. results. This is not the case with genetic screening programs, which are generally undertaken with groups of apparently healthy or asymptomatic individuals to determine who is predisposed to a disease or risks passing it on to descendants. In general, there is no professional-patient relationship, no opportunity to assess the psychosocial impact of testing on any single individual. It is therefore important when undertaking screening programs of the general population or certain at-risk groups to have specific objectives in mind, including therapy or preventive strategies. The programs should then be designed to best, achieve those objectives. For example, the PKU screening program of all newborns is done with the specific intention of identifying those children who must follow a specific diet to prevent mental retardation. Screening programs, such as the Tay Sachs programs developed in coordination with the Ashkenazi Jewish community, give participants information they have requested concerning reproductive implications. The sickle cell early 
screening of school-aged children of African descent undertaken in the United States in the past was not well coordinated with the community, was not designed to achieve discrete objectives, and re sulted in burdens for participants of stigmatization and discrimination. The situation would be different today, since many of the consequences of sickle cell disease are treatable, with early identification of children giving the best results.

Having genetic information about oneself, and providing genetic information to others, is not without risk. Knowledge of one's genetic profile may have little value for its own sake. It may have advantages or disadvantages for specific reasons, many of them personal. As a consequence, in undertaking their assessment of projected risk and anticipated benefit, IRB members must ask what purpose will be served by giving subjects their test results.,

Implications of Genetic Research with Indigenous and Other Communities. Research involving identifiable communities raises serious and novel ethical questions with which both researchers and institutional review boards (IRBs) must grapple. ${ }^{10}$ These communities include: (1) indigenous communities, having their own "social structures, common customs, and an acknowledged leadership," 11 and (2) groups that are identifiable by such factors as ethnic origin, isolated geographical locale, or status, such as disease condition. Research with communities is becoming increasingly common as geneticists search for disease-causing genes and clues to the origin of human populations.

Research with indigenous communities. Perhaps the best known example of genetic research involving indigenous communities is the Human Genome Diversity Project (HGDP), which aims to collect information on human genetic diversity, the origins and migration of human populations, and genetic factors related either to resistance or susceptibility to disease. ${ }^{12,13} \mathrm{Re}$ searchers are collecting material from members of roughly 500 isolated communities throughout the world. Each of the genetic samples will be preserved by the creation of an immortalized cell line, and then screened for dozens of genetic markers.

While not a genetic screening protocol in any clinical sense, the HGDP provides a cautionary example for both genetic researchers and the IRBs that review their proposals when they involve indigenous communities. Despite the fact that some planners of the HGDP carefully considered many of the relevant ethical issues, ${ }^{14}$ the study came under heavy fire from aboriginal groups and others on a number of grounds. ${ }^{15}$ Indigenous peoples were furious that they had been targeted for the study without being consulted. Some groups were opposed to the donation of blood or DNA samples on religious grounds. Others were opposed to the (potential) commercialization and patenting of human DNA. ${ }^{16,17}$

How can researchers avoid such damaging conflicts? What standards govern the conduct of research that involves aboriginal groups in North A merica or other communities outside of North America? And what can we learn from these standards that might apply to other communities, such as dispersed individuals who are identifiable by their ethnic origins, their isolated geographical locale, or by status such as disease condition.

All human experimentation is governed by the principles laid out in the Belmont Report: respect for persons, beneficence, and justice. ${ }^{18}$ While the traditional ethical analysis of research has focused on potential harms to individual research participants, research involving indigenous communities carries with it the risk of harming the community itself. Autonomous communities have their own politics, beliefs, and values; re searchers may, albeit unintentionally, damage any or all of these communal elements. In a community that undertakes decisions collectively, the mere act of seeking individual informed consent without prior communal consent may harm the community's political structure. Educating community members on something as seem- ingly innocuous as disease prevention may put traditional beliefs re garding disease causation and healing at risk. The conduct of research involving the creation of immortalized cell lines is likely to offend a community that believes in the principle of natural harmony. None of these problem cases is covered adequately by the Belmont principles. A new principle is needed: the principle of "respect for communities." 19

Respect for communities requires researchers to plan and conduct research in a way that not only minimizes social disruption within a community, but also in a manner that is culturally and politically sensitive. In particular, re searchers should respect the language, traditions, dignity, privacy, rights, and standards of the community. Just as researchers have an obligation to protect individual research subjects from harm, so too they must endeavour to protect communities from harm.

How should the principle of "respect for communities" be implemented? U.S. regulations are silent on the issue. International research may, according to Department of Health and Human Services (DHHS) regulations, be conducted according to the standards of host countries provided that "a Department or Agency head determines that the procedures prescribed by the institution afford protections that are at least equivalent to those provided in this [DHHS] policy." (45 CFR 46.101(h)). (Research conducted under the aegis of Food and Drug Administration regulations is not afforded this exemption. ${ }^{20}$ ) But what constitutes " protections that are at least equivalent"? Federal regulations at 45 CFR 46.101(h) specifically mention the Declaration of $\mathrm{H}$ elsinki, but according to the IRB Guidebook additional policies are required. ${ }^{21}$ Dickens and colleagues suggest that adherence to the International Ethical Guidelines for Biomedical Research Involving H uman Subjects (Council for International Organizations of Medical Sciences (ClOMS), 1993) may be sufficient. ${ }^{20}$ 
The CIOMS guidelines provide useful direction for geneticists and other researchers conducting international research. The guidelines require that: (1) persons in underdeveloped communities should ordinarily not be involved in research that could be carried out reasonably well in developed communities; (2) the research is responsive to the needs and priorities of the community; (3) researchers seek individual informed consent where possible; and (4) protocols be re viewed by an IRB that has among its members or consultants persons who are thoroughly familiar with the community and its customs. $^{22}$ Additionally, the CIOMS guidelines require that international research be reviewed in both the funding country and the host country and that the ethical standards of both countries be met (guideline 15).

But geneticists in the field and IRBs reviewing their research proposals need more explicit guidance-guidance that ultimately must come from communities themselves. One potential source of detailed information is found in guidelines for research on aboriginal peoples, prepared largely with the cooperation and input of indigenous peoples in Canada, Australia, and the United States. ${ }^{23-28}$ These documents contain elements common to all or most, relating to negotiation and consent, design and conduct of the research, ownership of the database or samples, and publication of results. Many of the provisions are of particular relevance to genetic research. Researchers and IRBs should, of course, consult any guidelines that apply specifically to the locale of the proposed research study.

Research with other "communities." What lessons can we cull from our dealings with indigenous communities? How should researchers treat other population groups, including patient and ethnic groups in North America?, Although patient and ethnic groups are often referred to as "communities," they frequently do not fit the definition of community given at the beginning of this section. $\mathrm{Pa}$ tient and ethnic groups in North
America are usually geographically dispersed; they are often without acknowledged leadership; and they may not have common social structures and customs apart from society at large. As a result, the application holus bolus of guidelines developed for indigenous communities to such groups is usually an error. For example, the absence of acknowledged leadership in the HIV/ AIDS "community" makes untenable the requirement for community consent for research participation. ${ }^{29}$

Nonetheless, it is important that researchers involve patient and ethnic groups in the design, conduct, analysis, and publication of studies that primarily involve and affect those groups. ${ }^{30}$ The patient population must be involved in research design to ensure that the study is responsive to the needs and priorities of medical consumers: Is the study question important? Will patients accept the proposed medical interventions? Is the outcome measure appropriate? Are recruitment procedures satisfactory? If this can be assured through a process of community consultation, enthusiasm for the study in the patient group will be engendered and, in turn, study recruitment and patient compliance will improve. ${ }^{31-33}$ The ethnic group must be involved, partly for this reason, and partly to ensure that the research remains sensitive to the beliefs and values of the group. Genetic research carries the risk of stigmatizing both patient and ethnic groups. Whenever research is focused on identifiable groups within our society, geneticists and IRBs must recognize that the risks and benefits of research are shared by both individual participants and the "community" to which they belong.

Genetics, Risk Assessment, and Confidentiality. Genetic information, perhaps more than any other health information, could have harmful social consequences for individuals when used in contexts such as employment, insurance, and immigration. Cases have been reported of people with asymptomatic genetic predisposi- tion who were excluded from employment or insurance. ${ }^{3436}$ Public awareness of such exclusions might significantly affect accrual in genetic trials. ${ }^{37-40}$ This impact on research as well as genuine concern for patients and research subjects has raised the question of how researchers can best protect the confidentiality of genetic data in their studies.

Risk assessment and insurance. One of the areas in which genetics could have a major impact is insurance. This is so, in particular, in the United States, where there is no universal health care coverage and where insurance is most frequently obtained through employment. Insurance underwriting, that is the determination of premiums on the basis of risk, uses health predictors. Genetic testing aims at detecting an increased risk for disease and can contribute to more precise and individualized underwriting. ${ }^{41}$ Until now, insurers have been reluctant to implement a system of genetic testing for the sole purpose of insurance. The costs of genetic testing and counseling and the fact that existing genetic tests mainly reveal risks that are frequently identifiable by other means, are among the most important reasons for this reluctance. ${ }^{42}$ But this does not mean that insurers currently do not use genetic information to assess insurability. Insurance application forms request data about genetic predisposition and ask permission to access medical files. When insurers have to pay out, they often verify the information given to them by accessing these files. It therefore becomes important to know whether researchers who undertake genetic testing can guarantee their subjects that the results will be kept confidential.

Confidentiality: promises and waivers. Research consent forms normally contain clauses of confidentiality. Moreover, codes of professional ethics impose a duty of confidentiality on physicians, ${ }^{43}$ geneticists, ${ }^{44}$ and other health care workers. They can be held liable for the consequences of illegitimate release of confidential information; Personal information contained in 
medical files belongs to those to whom this information pertains. These individuals can thus decide who should, and who should not have access to these intimate data, and thus can waive their right to confidentiality. Insurance contracts normally contain a clause permitting insurers to access medical files. While physicians and other health care workers are obliged to respect the confidentiality of medical information, they must also respect a patient's or subject's explicit authorization to give access. Codes of professional ethics provide that health care workers can divulge medical information when the patient permits them to do so.

Furthermore, the same codes contain another exception: physicians must divulge medical information if the law obliges them to do so. Not only does the law provide that health care workers have to respect the contractual stipulations of those toward whom they have a duty of confidentiality, but courts can also oblige physicians to give access without explicit waiver of confidentiality. This will be the case in court procedures where the issue is the state of health of a person and where parties obtain access to medical files in order to prepare a full and fair defense. Legal disputes related to life and health insurance frequently focus on the pre-existing medical condition of applicants. In these cases, insurers may obtain access to medical files, even when there is no explicit waiver of confidentiality.

Confidentiality and research files. How do these principles relate to research files? When access to medical files is requested, either by courts or on the basis of a waiver of confidentiality, can re searchers adequately protect re search subjects by refusing access?

There appears to be no standard for how or where research re sults should be maintained. Research subjects are recruited into genetics trials in a variety of ways: by their physicians who are also investigators; by probands who in turn recruit family members; by investigators-both physicians and nonphysicians-who advertise publicly or recruit through support groups or other lay organizations; by trial groups such as those associated with the National Cancer Institute who seek DNA samples from symptomatic subjects enrolled in trials of nongenetic therapies. There is also variety in how and where research data are kept. DNA samples may be stored with or without identifiers, with or without the possibility of retrieving further information from a subject's medical or research records (depending on the research protocol and the subject's consent). Investigators may or may not be located within institutions offering patient care. In some cases subjects will be informed of the re sults of their tests; in other cases they will not. An additional confounding factor arises when protocols provide that as clinically relevant information becomes available in the course of research, this will be used for the clinical treatment of research subjects and be included in their medical files. Furthermore, the object of research may itself be a treatment modality and therefore individual research results form an integral part of the medical record.

As a consequence of the variety of circumstances for both investigators and subjects, and also be cause of a lack of any clear policy direction or standard of practice, research results of an individual's genetic tests may be kept in patient medical files, or within a health care institution but intentionally separate from medical files, or within files in a research establishment unconnected with patient care.

Genetics is increasingly becoming a part of standard medical practice. Test results or other information from which test results can be deduced are more and more frequently integrated in medical files. $^{45}$ To the extent that genetic tests gain clinical relevance for ordinary medical treatment or prevention strategies, it may be very difficult to keep these data out of medical files. The first question re searchers and research ethics boards have to ask is whether it is appropriate to keep all such data out of medical files. This might not be appropriate if these data have clear clinical relevance for the treatment of patients, and integration in medical files is important for future treatment decisions or prevention strategies.

But even if genetic test results are maintained entirely separate from medical records, will re searchers always be able to maintain confidentiality against access by courts or insurers? When subjects have been informed about test results indicating an increased risk for health, can, or should, researchers promise that this information will remain confidential and will never be accessible to insurers? Insurance contracts are contracts of "utmost good faith" in which faithful exchange of information is essential. This exchange of information is necessary because insurance protects against uncertainty. And information given by applicants allows insurers to determine accurately the risk that an uncertain event will occur. If applicants would be allowed to withhold information from insurers, they would be in a position to hide major risk factors. To avoid adverse selection, insurance laws provide that contracts can be declared null and void if applicants withhold information that a reasonable insurer would have taken into consideration for determining insurability. This normally implies that applicants have to declare to insurers all relevant health information of which they are aware. They have to declare the results of genetic tests if these are relevant for assessing their health risks. Negative findings may result in lower insurance premiums; positive test results may lead to higher premiums or exclusion from insurance coverage. ${ }^{42}$

It might be argued that if subjects have not been informed about genetic test results, they do not know more than insurers. Applicants cannot use information that they do not possess. In these circumstances, the argument goes, they are not in a position that undermines the consensual basis of the contractual agreement. Howev-

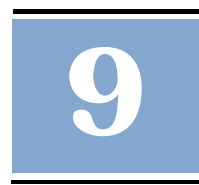


er, if people have been informed, they clearly have an obligation to declare the results of the tests. Courts might oblige researchers to give access to the results of these tests because they were relevant to assess the insurability of applicants. Applicants have an obligation to inform insurers accurately about the results of tests. If they declared that they tested negative for a genetic predisposition, insurers have to be able to verify this statement.

But what if researchers systematically make research files unlinked and unlinkable. to avoid third-party verification of genetic test results on individuals? Or what if insurers are not aware that people participated in genetic screening studies? Obviously, there could be ways to prevent third-party access to these data. But would it be accentable (or even legal) to participate in deceiving insurance companies through hiding medically relevant genetic information to which the subject has access? And would it be appropriate to advise this to research subjects? Insurers may obtain information about these test results by other means, for example by interviewing acquaintances of research participants. In such cases, insurance contracts can be retroactively annulled.

One of the difficulties with finding a fair resolution to the issue of third-party access to genetic test results comes from the fact that the technology is new and it has been used with relatively few individuals. While risk assessment is an integral part of the insurance business, some may feel that using genetic information against only those few for whom it is available will be discriminatory. Current estimates are that everyone has three to five serious predispositions which, under the "right" circumstances, will lead to serious illness or death. ${ }^{6}$ If medically relevant genetic information were available for all insurance applicants, the "playing field" for assessing risk would be more even. Another difficulty arises because much genetic information has unknown or incomplete clinical rele- vance, as discussed above. There is fear that genetic test results will be misinterpreted or exaggerated to deny insurance coverage or payout. For these and other reasons, some jurisdictions have passed or introduced legislation limiting the use of genetic information for insurance or employment purposes. ${ }^{42}$ Investigators and IRBs who want information about the relevance of such legislation to re search files, or under what circumstances research files could be accessed by the courts, should seek local legal advice.

Investigator and institutional responsibilities. What should IRBs expect from investigators concerning protection of confidentiality and what should investigators le gitimately offer? Researchers and IRBs need to be clear whether and why research results will or will not be disclosed to subjects. Prospective subjects should always be informed that genetic information carries with it social risks, both from personal knowledge and from third-party knowledge. For protocols where it is reasonable to provide test results to subjects, they should always have the option of not receiving them. And the clinical relevance of the genetic knowledge to be gained from the particular trial for the individual research subject should not be exaggerated by investigators. As for the measures necessary to protect confidentiality of patient data or DNA samples, protocols must describe an explicit plan for doing so. IRBs should ensure that adequate measures have been taken, whether by encryption, use of unique identi-

fiers, mandatory stripping of identifiers after a stated time period, encoding requiring IRB approval to relink data with subject or patient files, sequestering of records or, where appropriate, physical security measures. While insurance has been the focus of discussion here, other third parties (e.g., employers, immigration officials, parties in a paternity suit, etc.) may have an interest in accessing subject records. What will happen to those records when the investigator's funding is not renewed, or the investigator retires, or changes. fields of interest? This is a larger policy question for institutions, which should have in place mandatory procedures that protect research results to the maximum allowed by law.

\section{Conclusion}

IRBs need to assure that genetics protocols undergo the same rigorous review as nongenetics protocols. The schema provided integrates some of the new issues involving genetics research into the existing IRB review structure, accommodating the "critical path" we have suggested for an IRB to follow in reviewing genetic diagnostic and screening protocols. IRBs should use the issues addressed by the schema not only to review individual protocols, but also to determine whether they or their institutions ought to develop local policies relevant to such issues as DNA banking, commercial interests, disclosure, or consent.

Our discussion of issues suggests that IRBs must recognize any uncertainties involved in clinical prediction and assure that they are clearly disclosed to prospective subjects. The impact of many protocols on the community level suggests that IRBs might need to reorient their focus so that it does not rest exclusively on the integrity of individual research subjects, but extends to affected groups or communities. And individuals entering genetics protocols should be able to expect confidentiality for their data or samples to the greatest possible extent. Current limits on the ability to protect confidentiality may require changes in law or social policy. Where there are limits to what is feasible, those limits must be adequately disclosed to prospective subjects.

\section{Acknowledgments}

The authors wish to thank Angela Campbell for her valuable research assistance. This work was funded by the Medical Research Council's (MRC) Canadian Genome Analysis \& Technology Program and a joint grant from the MRC and the Social Sciences and Humanities Research Council of Canada. 


\section{References}

1. See our first paper in this series published in IRB: Glass KC, Weijer C, Palmour RA, et al.: Structuring the review of human genetics protocols: gene localization and identification protocols. IRB 1996; 18(4): 1-9.

2. US Congress, Office of Technology Assessment: Cystic Fibrosis and DNA Tests: Implications of Carrier Screening. Washington, D.C.: Office of Technology Assessment, 1992.

3. Wall N, Cackle H: Reporting the assessment of screening and diagnostic tests. British Journal of $\mathrm{Ob}$ stetrics and Gynaecology 1989; 96: 389-96.

4. Campbell ME, Machine D: Medical Statistics: A Commonsense Approach, 2nd ed. West Sussex, England: John Wiley \& Sons Ltd., 1993.

5. National Academy of Sciences: Ge netic Screening Programs: Principles and Research. Washington, D.C.: National Academy of Sciences, 1975.

6. Vogel F, Motulsky AG: Human Genetics: Problems and Approaches. Berlin: Springer-Verlag, 1994.

7. Institute of Medicine, Assessing $\mathrm{Ge}$ netic Risk, 1994.

8. Clinical Laboratories Improvement Act of 1967, 42 USCS ss. 263a.

9. Reilly P: When should an investigator share raw data with the subjects? IRB 1980; 2(9): 4-5, 12.

10. Issues involving indigenous communities cut across both "genehunting studies" and "genetic screening and diagnostic studies." For a discussion of other issues related to "gene-hunting studies see our previous paper in IRB: Glass KC et al., 1996.

11. Council for International Organizations of Medical Sciences (CIOMS): International Ethical Guidelines for Biomedical Research Involving Human Subjects. Geneva: CIOMS, 1993.

12. Roberts L: Genome diversity project: anthropologists climb (gingerly) on board. Science 1992; 258: 1300-1.

13. Lewin R: Genes from a disappearing world. N ew Scientist 1993; 138: 25-9.

14. North American Regional Committee of the Human Genome Diversity Project, Proposed Model Ethical Protocol for Collecting DNA Samples (Draft). September, 1995; Human Genome Organization (HUGO) Ethics Committee: State ment on the Principled Conduct of Genetic Research. March, 1996.

15. Kahn P: Genetic diversity project ties again. Science 1994; 266: 720-2.

16. Declaration of Indigenous Peoples of the Western Hemisphere regarding the Human Genome Diversity Project. Phoenix, Arizona. 19 February, 1995.
17. Dickson D: Whose genes are they anyway? Nature 1996; 381: 11-4.

18. National Commission for the Protection of Human Subjects of Biomedical and Behavioral Research: The Belmont Report: Ethical Principles and Guidelines for the Protection of Human Subjects Research. OPRR Reports; 18 A pril 1979: 1-8.

19. Levine RJ: Validity of consent procedures in technologically developing countries. In:. Bankowski Z, Howard-Jones $N$, eds. Human Experimentation and Medical Ethics. Geneva: Council for International Organizations of Medical Sciences, 1982: 16-30.

20. Dickens BM, Gostin L, Levine RJ: Research on human populations: national and international ethical guidelines. Law, M edicine, and Health Care 1991; 19: 157-61.

21. Office for Protection from Research Risks: Protecting Human Subjects: Institutional Review Board Guidebook. Washington, D.C.: U.S. Government Printing Office, 1993.

22. Council for International Organizations of Medical Sciences: International Ethical Guidelines for Biomedical Research Involving Human Subjects. Geneva: CIOMS, 1993: guideline 8.

23. Canada Tri-Council Working Group: Code of Conduct for Research Involving Humans (Draft document, March 1996). Ottawa: Minister of Supply and Services, 1996.

24. U.S. Indian Health Service: Draft IHS Guidelines About the Collection and $U$ se of Research Specimens. Washington, D.C.: Indian Health Service, 7 June 1996.

25. Canada Royal Commission on Aboriginal Peoples: Ethical Guidelines for Research. Ottawa: N.d.

26. Association of Canadian Universities for Northern Studies: Ethical Principles for the Conduct of $\mathrm{Re}$ search in the $\mathrm{N}$ orth. Ottawa: ACUNS, 1982.

27. Australia National Health and Medical Research Council: Guidelines on Ethical $M$ atters in Aboriginal and Torres Strait Islander Health Research. Publication no. E13. Canberra: NHMRC, 1991.

28. American Indian Law Center: $M$ odel Tribal Research Code: With $M$ aterials for Tribal Regulation for Research and Checklist for Indian $\mathrm{H}$ ealth Boards. Albuquerque, N.M.: American Indian Law Center, 1994.

29. Spiers HR: Community consultation and AIDS clinical trials, part III. IRB 1991; 13(5): 3-7.

30. Weijer C: Our bodies, our science. The Sciences 1995, May/June: 41-5.

31. Valdiserri RO, Tama GM, Ho M: The role of community advisory committees in clinical trials of antiHIV agents. IRB 1988; 10(4): 5-7.

32. Levine C, Dubler NN, Levine RJ: Building a new consensus: ethical principals and policies for clinical research on HIV/AIDS. IRB 1991; 13(1-2): 1-17.

33. Sutherland HJ, Meslin EM, Till JE: What's missing from current clinical trial guidelines? A framework for integrating science, ethics, and the community context. Journal of Public Health Policy 1994; 5: 297303.

34. Billings $P$, et al.: Discrimination as a consequence of genetic testing. A merican Journal of Human Genetics 1992; 50: 476.

35. Natowictz MR, Alper LK, Alper SJ: Genetic discrimination and the law. American Journal of Human Genetics 1992; 50: 465.

36. Alper J, et al.: Genetic discrimination and screening for hemochromatosis. Journal of Public $\mathrm{Health}$ Policy 1994; 15(3): 345.

37. Gostin L: Genetic discrimination: the use of genetically based diagnostic and prognostic tests by employers and insurers. A merican Journal of Law \& Medicine 1991; 17(1-2): 109.

38. Nys $\mathrm{H}$, et al.: Predictive Genetic Information and Life Insurance: Legal Aspects. Towards European Community Policy? Maastricht: University of Limburg, 1993.

39. Some argue that insurability will not be affected by the rise of genetic tests. See Pokorski RJ: Use of genetic information by private insurers. In: Murphy TF, Lappe MA, eds. Justice and the Human Genome Project. Berkeley: University of California Press, 1994: 91-109.

40. Lowden JA: Certificates of confidentiality. A merican Journal of Human Genetics 1996; 58(2): 436-7.

41. Memorandum from the Association of British Insurers in House of Commons, Science and Technology Committee: Third Report; H uman Genetics: The Science and Its Consequences, Volume IV, Minutes of Evidence. London: HMSO, 1996.

42. Lemmens $T$, Bahamin P: Genetics in Life, Disability and Additional $\mathrm{H}$ ealth Insurance in Canada A Comparative Legal and Ethical A nalysis. Report submitted to the Medical, Ethical, Legal and Social Issues Advisory Committee of the Canadian Genome Analysis \& Technology Programme. Montreal: Centre de recherche en droit public, 1996.

43. Canadian Medical Association: Code of Ethics, $\S 6$.

44. Canadian College of Geneticists: Professional and Ethical Guidelines, $\$ 10$.

45. Jecker NS: Genetic testing and the social responsibility of private health insurance companies. Journal of Law, M edicine \& Ethics 1993; 21(1): 109.

See page 13 for references to Table 1.

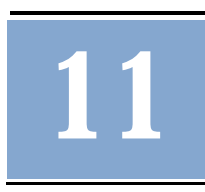




\section{Benjamin Freedman 1951-1997}

enjamin Freedman, professor at the Biomedical Ethics Unit in the Faculty of Medicine of McGill

University and member of the editorial board of IRB, died shortly after palliative surgery for stomach cancer on 20 March 1997. Benjy's intellectual legacy includes many important publications in several specialties in the field of bioethics; I shall concentrate on his outstanding contributions to our understanding of the ethics of research involving human subjects.

Benjy wrote that the goal of bioethics is " the exposure of muddled and wrong-headed concepts, to clear the way for a healthy growth of ideas." This is exactly what Benjy did so well and so often. Time after time, when I read his publications on some of bioethics' most recalcitrant problems, I thought, "This is so simple and so clearly correct. Why didn't I think of this before?" Let us consider some examples.

Against unjustified paternalism: "Perhaps the worst which we may do to a man is to deny him his humanity, for example, by classifying him as mentally incompetent when he is, in fact, sane. It is a terrible thing to be hated or persecuted; it is far worse to be ignored, to be notified that you 'don't count."'

During the classical Ramsey-McCormick debate over whether "nontherapeutic experiments" on children were ever permissible-a debate that focused on the consent of (or for) the child: " $[T]$ he fundamental problem with those who would forbid all experimentation upon children is that they confuse consent in adults with proxy consent for children. ... [T] The function of informed consent is to respect the autonomy and dignity of the individual. This cannot be the function of proxy consent. (The child, unlike the adult, has a right not to liberty but to custody.) . . . [T] here is only one fundamental right possessed by minors, a right to be protected and aided in development. . . . All other rights which a child possesses, all other duties which we have towards children, are derivative from this single right, and are void when inconsistent with it."

On replacing the standard [at the time] ethical justification of randomized clinical trials to which Benjy had given the name "theoretical equipoise": 'Theoretical equipoise exists when, overall, the evidence on behalf of two alternative treatments is exactly balanced. This evidence may be derived from a variety of sources, including data from the literature, uncontrolled experience. . . and, perhaps, a 'gut' feeling or 'instinct'... . [Theoretical equipoise is] overwhelmingly fragile, conceptually odd and ethically irrelevant."

Benjy recommended "clinical equipoise" as more satisfactory in all respects. "To understand the alternative, preferable interpretation of equipoise, we need to recall the basic reason for conducting clinical trials: there is a current or imminent conflict in the clinical community over what treatment is preferred for patients in a defined population P. The standard is A, but some evidence suggests that B will be superior . . . Each side recognizes that the opposing side has evidence to support its position, yet each still thinks that its view is correct. A clinical trial is instituted with the aim of resolving this dispute... .

"[These are] the formal conditions under which a trial would be ethical: At the start of the trial there must be a state of clinical equipoise ... . and the trial must be designed in such a way as to make it reasonable to expect that, if it is successfully concluded, clinical equipoise would be disturbed. ... . [T]he results of the successful trial should be convincing enough to resolve the dispute among clinicians."

Benjy's latest book, D uty and H ealing: Foundations of a Jewish Bioethics, which he considered his most important work, is published in the Internet (http:/ / www.mcgill.ca/ ctrg/ bfreed/). His choice of this mode of publication attests to his unselfishness; his determination to engage a large and diverse audience of scholars, professionals, and laity; and his wish to be able to revise promptly in response to constructive criticism.

Benjy was a truly large-spirited man; this was expressed in virtually every facet of his life. It was demonstrated vividly in his deep commitment to Judaism and in his devotion to his family. He believed that the ethicist had a special obligation to academic integrity and tried to live each day accordingly. He had a marvelous sense of humor. He was a blunt, severe, and affectionate critic and expected the same in return-at least the bluntness and severity. And when circumstances called for it, he was a most compassionate source of support.

Great scholars and teachers often live on through their writings and through the work of their students. Benjy knew this. In the few weeks between his learning his diagnosis and his death, he made a list of his works in progress. He called his friends and his colleagues (many of whom were present or past members of his Clinical Trials Research Group at McGill) and asked them to see to it that these works would be continued. If we failed to do this, he threatened, he would come back to haunt us. If we were confident that our failure in this regard would bring him back, we would be greatly tempted.

- Robert J. Levine Editor 


\section{Table 1 References}

1. 45 CFR 46.111(a)(1)(I).

2. Medical Research Council of Canada (MRC): Guidelines on Research Involving Human Subjects, sec.llC: Methodology and Ethics. Ottawa: MRC. 1987.

3. Shapiro SH, Louis TA, eds: Clinical Trials: Issues and A pproaches. New York: Marcel Dekker, Inc., 1983.

4. Friedman L, Furburg C, DeMets D: Fundamentals of Clinical Trials. 3rd ed. St. Louis: Mosby, 1996.

5. Lander E, Kruglyak L: Genetic disection of complex traits: guidelines for interpreting and reporting linkage results. Nature Genetics 1995; 11(3): 241-7.

6. See our first paper in this series published in IRB: Glass KC, Weijer C, Palmour RA, et al.: Structuring the review of human genetics protocols: gene localization and identification protocols. IRB 1996; 18(4): 1-9.

7. Weir RF, Horton, JR: DNA banking and informed consent, Part 1. IRB 1995; 17(4): 1-4; Part 2. IRB 1995; 17(5-6): 1-8.

8. Clayton EW, Steinberg KK, Khoury MJ, et al.: Informed consent for genetic research on stored tissue samples. JAM A 1995; 274: 1786-92.

9. Knoppers BM, Laberge CM: Re search and stored tissues: persons as sources, samples as persons. JAM A 1995; 274: 1806-8.

10. 45 CFR 46.111(a)(7).

11. National Council on Bioethics in Human Research (NCBHR): Report on Research Involving Children. Ottawa: NCBHR, 1992.

12. OPRR, 1994

13. Keyserlingk EW, Glass KC, Kogan S, Gauthier S: Proposed guidelines for the participation of persons with dementia as research subjects. Perspectives in Biology and $M$ edicine 1995; 38(2): 319-62.

14. 45 CFR 46.111(a)(2).

15. Freedman B, Fuks A, Weijer C: De marcating research and treatment: a systematic approach for the analysis of the ethics of clinical research. Clinical Research 1992; 40(4): 653-60.

16. 45 CFR 46.111(a)(1).

17. Kass $\mathrm{N}$ : Participation in pedigree studies and the risk of impeded access to health insurance. IRB 1993; 15(5): 7-10.
18. Royal Commission on Aboriginal Peoples: Ethical Guidelines for Research 1993. Ottawa: N.d..

19. American Indian Law Center: M odel Tribal Research Code: With $M$ aterials for Tribal Regulation for Research and Checklist for Indian $\mathrm{H}$ ealth Boards. Albuquerque, N.M.: American Indian Law Center, 1994.

20. Centre for Independent Living, 1989

21. Levine C, Dubler NN, Levine RJ: Building a new consensus: ethical principles and policies for clinical research on HIV/ AIDS. IRB 1991; 13(1-2): 1-17.

22. Weijer C: Our bodies, our science. The Sciences 1995, May/ June: 41-5.

23. MacKay C: Discussion points in research related to the human genome. Human Gene Therapy 1993; 4: 447-95.

24. Reilly PR, Boshar MF, Holtzman SH: Ethical issues in genetic research: disclosure and informed consent. Nature Genetics 1997; 15: 16-20.

25. 45 CFR 46.116(a)(8).

26. 45 CFR $46.116(b)(3)$.

27. Levine RJ: Research that could yield marketable products from human materials: the problem of informed consent. IRB 1986; 8(1): 6-7.

\title{
"There is no substantive due process right to conduct human-subject research": The Saga of the Minnesota Gamma Hydroxybutyrate Study
}

\author{
by Dale E. Hammerschmidt
}

Conflict-of-Interest Disclaimer: I was a member of the investigative subcommittee that rendered the decision which prompted the lawsuit resulting in the ruling described in this essay. My perspective is therefore obviously that of an IRB member and defendant.

\section{"There is no substantive due process right to conduct human-subject research . . ."1}

ith these words, Federal District Judge James Rosenbaum (Fourth Division, District of Minnesota) on 9 July 1996 formally recognized the concept that the opportunity to conduct research upon human subjects is a privilege, rather than a right. This distinction has impor-

Dale E. Hammerschmidt, M.D. F.A.C.P., is associate professor of medicine and an institutional review board chair at the University of Minnesota. tant implications for IRB process, including the allocation of burden of proof regarding the allowability of particular research, the nature of the default finding in the event that evidence is unconvincing, and the nature and extent of the process which is due and appropriate when the IRB finds itself faced with the unpleasant task of deciding whether to revoke or restrict its approval of an investigator or a body of work.

The statement was made in the context of an order granting summary judgment in favor of the defendants-the University of Minnesota and its IRB (and seven named members of the IRB's investigative subcommittee) -in a suit brought by a suspended principal investigator who claimed he had been denied due process in IRB proceedings.

A study had been begun testing whether an experimental drug was an effective adjunct in the treatment of opium dependency. An investigational new drug (IND) and IRB approval were in place. Within a few months, the IRB received from a member of the principal investigator's (PI's) academic department a written statement of concern, re porting that proper informed consent was not being obtained, raising concerns about other possible problems, and naming the sources of the information. The PI was made aware of the letter (and was given a copy), and he suspended the study immediately. After an initial inquiry, the IRB suspended the PI's involvement in other studies, as well, and initiated a formal investigation.

During the investigation, the $P$ was allowed to present his side of the story, including several hours of attorney-assisted testimony be fore the investigative panel. He was not, however, granted the op- 